\title{
Investigation of the Effect of Rice Wine on the Metabolites of the Main Components of Herbal Medicine in Rat Urine by Ultrahigh-Performance Liquid Chromatography-Quadrupole/Time-of-Flight Mass Spectrometry: A Case Study on Cornus officinalis
}

\author{
Gang Cao, ${ }^{1,2,3}$ Hao Cai, ${ }^{1,3}$ Xianke Yue, ${ }^{2}$ Sicong Tu, ${ }^{4}$ Baochang Cai, ${ }^{1,2,3,5}$ and Zhiwei Xu ${ }^{2}$ \\ ${ }^{1}$ Engineering Center of State Ministry of Education for Standardization of Chinese Medicine Processing, \\ Nanjing University of Chinese Medicine, Nanjing 210023, China \\ ${ }^{2}$ Research Center of TCM Processing Technology, Zhejiang Chinese Medical University, Hangzhou 310053, China \\ ${ }^{3}$ National First-Class Key Discipline for Science of Chinese Materia Medica, Nanjing University of Chinese Medicine, \\ Nanjing 210023, China \\ ${ }^{4}$ Faculty of Medicine, University of New South Wales, Sydney, NSW 2031, Australia \\ ${ }^{5}$ Nanjing Haichang Chinese Medicine Group Corporation, Nanjing 210061, China
}

Correspondence should be addressed to Hao Cai; haocai_98@126.com and Baochang Cai; bccai@126.com

Received 4 February 2013; Revised 29 March 2013; Accepted 30 March 2013

Academic Editor: Yong Qing Yang

Copyright (c) 2013 Gang Cao et al. This is an open access article distributed under the Creative Commons Attribution License, which permits unrestricted use, distribution, and reproduction in any medium, provided the original work is properly cited.

Ultrahigh-performance liquid chromatography-quadrupole/time-of-flight mass spectrometry (UPLC-QTOF/MS) was developed for rapid and sensitive analysis of the effect of rice wine on the metabolites of the main components of herbal medicine in rat urine. Using Cornus officinalis as a model of herbal medicine, the metabolite profiles of crude and processed (steaming the crude drug presteeped in rice wine) Cornus officinalis extracts in rat urine were investigated. The metabolites of Cornus officinalis were identified by using dynamic adjustment of the fragmentor voltage to produce structure-relevant fragment ions. In this work, we identified the parent compounds and metabolites of crude and processed Cornus officinalis in rats. In total, three parent compounds and seventeen new metabolites of Cornus officinalis were found in rats. The contents of the parent compounds and metabolites in vivo varied significantly after intragastric (i.g.) administration of aqueous extracts of crude and processed Cornus officinalis. Data from this study suggests that UPLC-QTOF/MS could be used as a potential tool for uncovering the effects of excipients found in the metabolites of the main components of herbal medicine, in vivo, to predict and discover the processing mechanisms of herbal medicine.

\section{Introduction}

The processing of Chinese materia medica is based on traditional Chinese medicine (TCM) and has undergone continual development and refinement for thousands of years. Traditional processing and treatment of TCM utilize a range of decoction pieces, with the aim of altering the nature of the medicine to accommodate different clinical dispensings and preparation requirements $[1,2]$. During processing, fire and wine are utilized in heat and excipient treatments in many herbs, respectively [3]. The processing of Chinese materia medica with excipients has a long history and the efficacy of treatment can be enhanced by using a combination of excipient treatments. There is a close relationship between the nature of Chinese materia medica and excipient treatments, through the collaboration and regulatory roles of excipients. As a result, the inherent property of such medicine can be improved through these processes to improve its treatment efficacy, which is often achieved by heating the medicine and excipient together. Solid excipients are mainly 
used to suppress the toxicity, while liquid excipients are used to enhance the treatment efficacy [4].

In processing TCM, wine is typically used as a gas component. It is believed that wine has the function of promoting blood circulation for removing obstruction in collaterals, strengthening the spleen and stomach, and removing foul odors $[5,6]$. Through modern medicine, these therapeutic efficacies have been demonstrated as alcohol can dilate blood vessels to enhance cerebral blood flow, stimulate the central nervous system, and improve circulatory of the digestive system [7]. For processing TCM, rice wine is one of the most commonly used liquid excipients. Typically, rice wine is used for steeping, boiling, and steaming herbs, or making various pills and medicated wine [8]. Rice wine contains large amounts of proteins, carbohydrates, vitamins, organic acids, esters, and minerals [9]. During the saccharification and fermentation process of rice wine production, starch and protein are degraded into oligosaccharides, peptides, amino acids, and other ingredients that are readily absorbed by the human body, thus making rice wine a highly nutritious supplement. In addition, rice wine serves as a good organic solvent and has good solubility for a variety of chemical compounds and good tissue penetration capability. When the drugs are heated with wine, rice wine can change the property of medicine, lead the medicine uplink, and change the ups and downs of the Chinese medicine. It can also enhance drug efficacy and reduce foul taste and corrosion. Therefore, the processing of Chinese materia medica using rice wine offers many clinical benefits.

Dried sarcocarp of Cornus officinalis Sieb. et Zucc (Cornaceae) is a herbal medicine widely used in TCM for medical, food sanitation, and cosmetic purposes [10]. Clinically, it is used both in its crude herbal form and as a processed product [11]. While potent unprocessed, pharmaceutical processing may reduce toxicity or side efficacies, potentiate the beneficial effects, change the pharmacological properties, preserve active constituents, facilitate administration, improve flavor or eliminate unpleasant taste, and increase purity of herbal medicine [12, 13]. Extensive phytochemical and pharmacological studies of Cornus officinalis have isolated and characterized a total of 10 iridoids, most of which have been proven to have bioactive properties for the prevention and treatment of diabetic nephropathy and kidney deficiency, anti-inflammation, antivirus and antioxidation [14-16]. Cornus officinalis, after being stewed with yellow rice wine, has a stronger efficacy on nourishing kidneys, astringing semen, and reducing urination. It has been used diffusely for curing dizziness, coldness, pain in the waist, frequent micturition, enuresis, impotence, and prospermia [17]. Furthermore, Cornus officinals warmly dredges up the dint of wine and reduces its acidity.

Within the literature, the majority of studies examining drug metabolism have been based on studies in which the liver was used as the experimental organ [18]. It is now clear that kidney also plays a major role in drug metabolism, as drug compounds and metabolites are excreted into the urine. Although most pharmacokinetic parameters of iridoids, such as morroniside, loganin, and sweroside, in Cornus officinals have been investigated [19-21], there is no report of renal excretion of active constituents and metabolites of main components in crude Cornus officinalis and its processed form. The aim of our study was to examine whether the absorption and metabolism of active components in Cornus officinalis through renal excretion were altered after processing using rice wine. In the present study, we employed a new and rapid ultrahigh-performance liquid chromatography-quadrupole/time-of-flight mass spectrometry (UPLCQTOF/MS) method to investigate the effect of rice wine on the metabolites of the main components of Cornus officinalis in rat urine.

\section{Experimental}

2.1. Materials, Chemicals, and Reagents. Crude Cornus officinalis was acquired from Henan suppliers and its processed form was treated according to the Chinese Pharmacopoeia (2010 eds.). HPLC grade acetonitrile and methanol were obtained from Merck (Darmstadt, Germany) and Fisher Scientific Corporation (Loughborough, UK), respectively. Deionized water was purified using the Milli-Q system (Millipore, Bedford, MA, USA) and HPLC grade formic acid was purchased from Honeywell Company (Morristown, NJ, USA). Loganin was purchased from the National Institute for the Control of Pharmaceutical and Biological Products (Beijing, China). Morroniside and sweroside were obtained from Shanghai Shangyi Biotechnology Co. Ltd. (Shanghai, China). HPLC analysis indicated that the purities of all reference compounds were greater than $98 \%$. All remaining chemicals were of analytical grade and commercially available.

\subsection{Instrumentation and UPLC-QTOF/MS Conditions.}

Chromatography was performed using an ACQUITY $\mathrm{C}_{18}$ BEH column $(150 \mathrm{~mm} \times 2.1 \mathrm{~mm}$ i.d., $1.7 \mu \mathrm{m})$ and CQUITYUPLC system (Waters Corp., Milford, MA, USA). The column was maintained at $40^{\circ} \mathrm{C}$ with a gradient elution of $0.1 \%$ formic acid in acetonitrile (solvent A) and $0.1 \%$ formic acid in water (solvent B) at $0-4.5 \mathrm{~min}(1-8.4 \% \mathrm{~A})$, $4.5-8 \min (8.4-9 \% \mathrm{~A}), 8-16 \mathrm{~min}(9-75 \% \mathrm{~A})$, and $16-17 \mathrm{~min}$ (75-99\% A). The flow rate was $0.45 \mathrm{~mL} / \mathrm{min}$, and $5 \mu \mathrm{L}$ aliquot of each sample was injected into the column. The eluent was then introduced to the mass spectrometer directly, that is, without a split.

The eluent was introduced into the synapt high-definitionmass spectrometer (Waters Corp., Milford, MA, USA) analysis. The optimal conditions were as follows: capillary voltage of $2.5 \mathrm{kV}$, sampling cone voltage of $20 \mathrm{~V}$, cone gas flow of $10 \mathrm{~L} / \mathrm{h}$, and desolvation gas flow of $700 \mathrm{~L} / \mathrm{h}$. The source and desolvation gas temperature were kept at 110 and $350^{\circ} \mathrm{C}$, respectively. The data were collected and analyzed using Masslynx V 4.1 and MetaboLynx software. The mass spectrometric data were collected in full-scan mode; the $\mathrm{m} / \mathrm{z}$ was from 100 to 1000 in positive and negative ions.

2.3. Preparation of Sample Solutions. $100 \mathrm{~g}$ of powdered Cornus officinalis and its processed samples were soaked in $200 \mathrm{~mL}$ of water for $2 \mathrm{~h}$ at room temperature and thereafter refluxed for $2 \mathrm{~h}$, respectively. The filtrate was collected and the residues were then refluxed twice in $1000 \mathrm{~mL}$ of water 


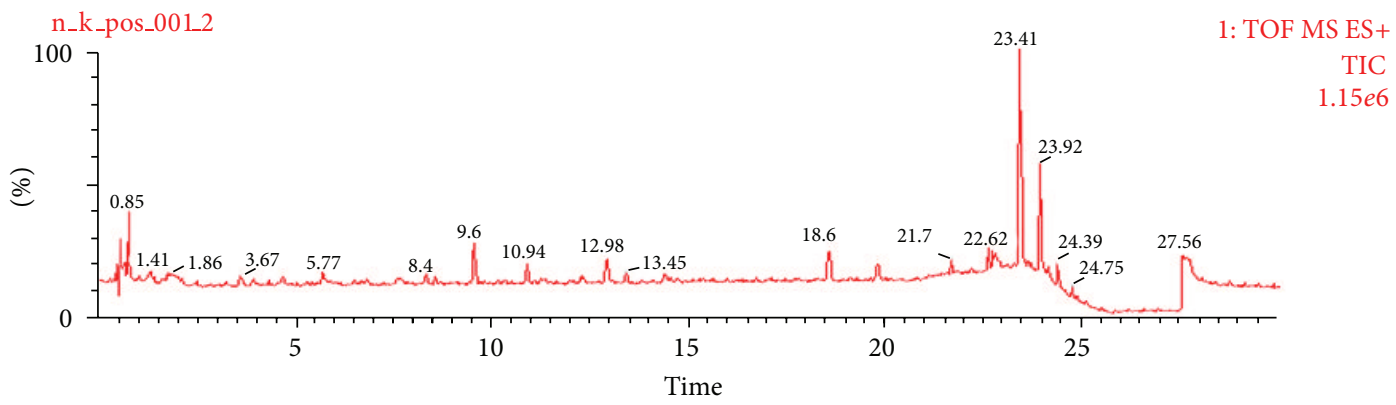

(a)

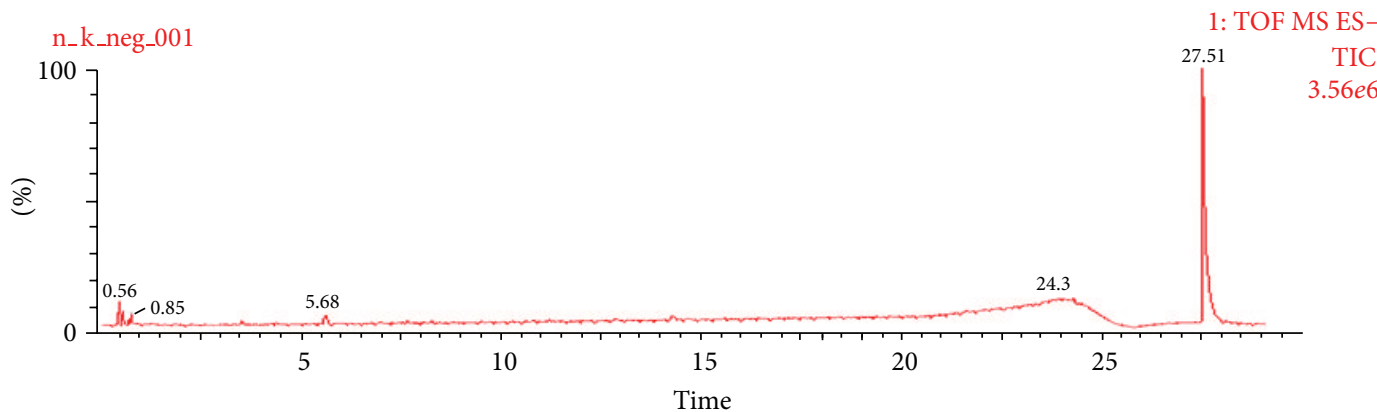

(b)

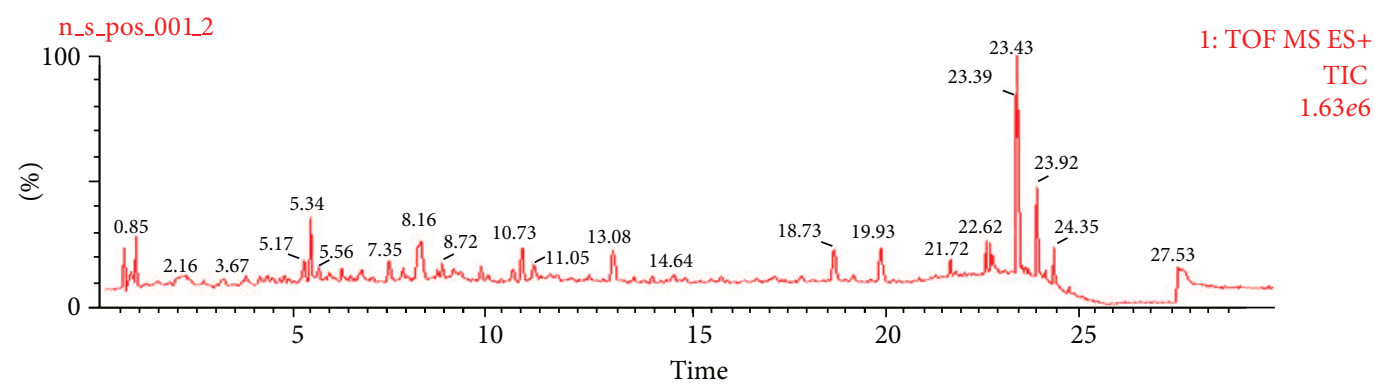

(c)

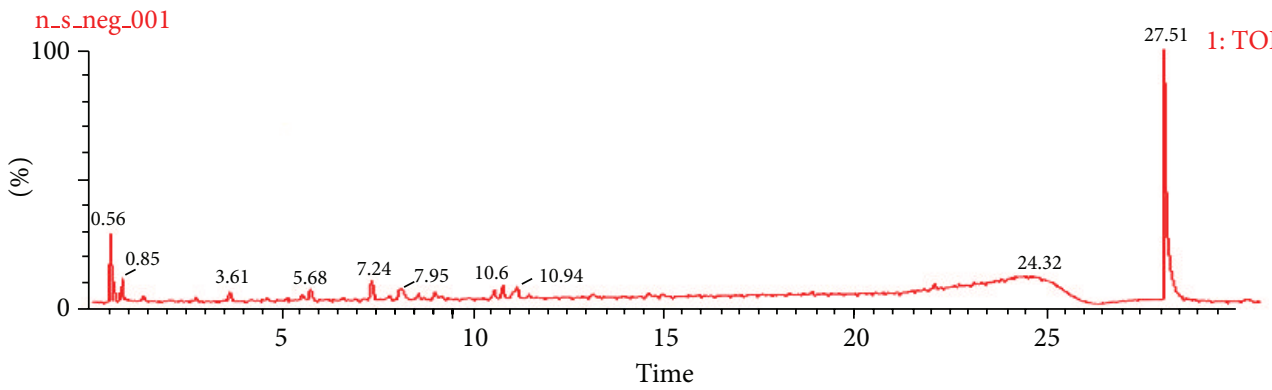

(d)

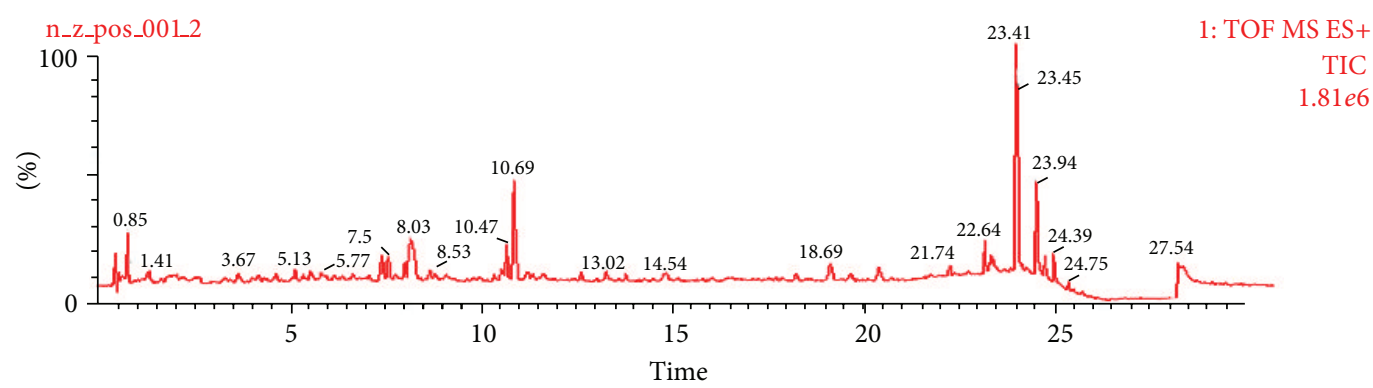

(e)

Figure 1: Continued. 


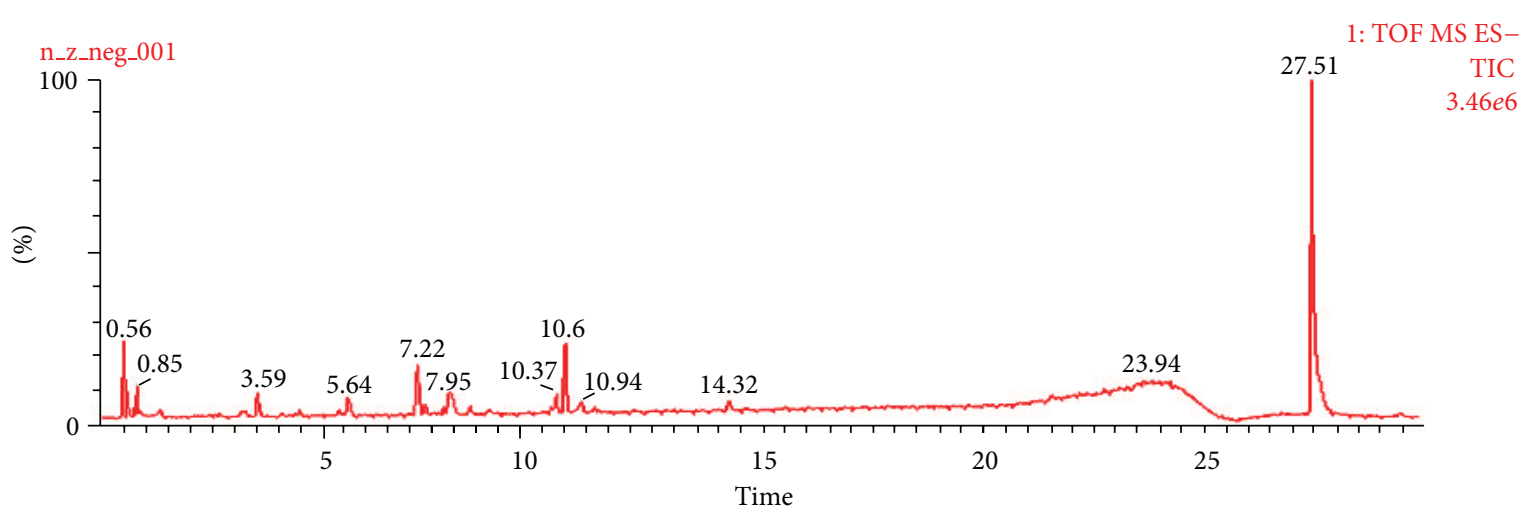

(f)

Figure 1: Total ion chromatograms of rat urine samples in positive and negative ion modes: (a) blank rat urine in positive mode; (b) blank rat urine in negative mode; (c) rat urine collected after administration of crude Cornus officinalis in positive mode; (d) rat urine collected after administration of crude Cornus officinalis in negative mode; (e) rat urine collected after administration of processed Cornus officinalis in positive mode; and (f) rat urine collected after administration of processed Cornus officinalis in negative mode.

for $1.5 \mathrm{~h}$. The three filtrates were combined and evaporated to the final volume of $100 \mathrm{~mL}$ under reduced pressure at a temperature not exceeding $60^{\circ} \mathrm{C}$.

\subsection{Animals, Drug Administration, Biological Sample Collec-} tion, and Preparation. Fifteen male adult Sprague-Dawley rats weighing approximately $300 \mathrm{~g}$ were obtained from the Laboratory Animal Center of Zhejiang Academy of Medical Sciences (Zhejiang, China). Animals were acclimatized for at least 5 days with alternating $12 \mathrm{~h}$ dark/light cycles in a climatecontrolled room with the temperature maintained at $22 \pm 1^{\circ} \mathrm{C}$, and a relative humidity of $60 \pm 10 \%$. Water and standard laboratory food were available ad libitum. All experiments were performed according to the guidelines for the care and use of animals as established by Zhe Jiang University.

The rats were equally divided into three groups (group A: crude Cornus officinalis group, $n=5$; group B: processed Cornus officinalis group, $n=5$; group C: control group, $n=5$ ) and housed individually in metabolic cages for the collection of urine samples. The rats were fed with standard laboratory food as well as water, ad libitum, and acclimatized to the facilities for 1 week prior to the start of experiments. The animals were fasted overnight with free access to water before the test. Crude Cornus officinalis and its processed extracts were administered to each rat in groups A and B, respectively, by traditional oral gavage at a dose of $2 \mathrm{~mL}$. Crude Cornus officinalis and its processed extracts were administered once daily for 1 week, while the equivalent volume of distilled water was orally administered to each rat in the control group (group C). Urine samples were collected after 1 week following administration. The volume of each sample was accurately measured and stored at $-80^{\circ} \mathrm{C}$ for preservation.

For analysis preparation, urine samples $(200 \mu \mathrm{L})$ were transferred to a $1.0 \mathrm{~mL}$ Eppendorf tube and acetonitrile $(600 \mu \mathrm{L})$ was added. This mixture was vortex-mixed for $2 \mathrm{~min}$ and centrifuged at $4,000 \mathrm{rpm}$ for $5 \mathrm{~min}$. The supernatant was separated out and blowed dry with nitrogen at $40^{\circ} \mathrm{C}$. The residue was then reconstituted in $100 \mu \mathrm{L}$ acetonitrile and mixed to make final testing samples. A $5 \mu \mathrm{L}$ aliquot of the final testing samples was injected into the UPLC-QTOF/MS system for analysis after centrifugation at $15,000 \times \mathrm{g}$ for $15 \mathrm{~min}$.

2.5. Data Processing. The mass data analysis was carried out using MetaboLynx and Masslynx V 4.1 (Waters Corp., Milford, MA, USA) for in vivo metabolite identification. The data was processed and mass full-scan raw data were collected through MSE acquisition. The UPLC-QTOF/MS data was detected and noise reduced in both the UPLC and MS domains, such that only true analytical peaks were further processed by the software (e.g., residual noise spikes were rejected).

\section{Results and Discussion}

3.1. UPLC-QTOF/MS Identification of the Main Active Components in Rat Urine. Iridoid glycosides and their metabolites are main components and active compounds in Cornus officinalis. In the current experiment, we expected that in addition to the major iridoid glycosides in Cornus officinalis extract, several metabolites would be detected in rat urine. From our results, we identified three iridoid glycosides in crude Cornus officinalis and its processed extracts, including morroniside, loganin, and sweroside, by comparing their retention times and MS data with established standards. The ion chromatograms of three iridoid glycosides and their metabolites are presented in Figure 1, and the monitored ions of each compound are listed in Table 1. The identification of each compound is outlined below.

\subsection{Identification of Parent Compounds and Related Metabolites}

3.2.1. Analysis of Parent Compound 1 and its Metabolites. Compound 1 showed an $[\mathrm{M}+\mathrm{COOH}]^{-}$ion at $m / z 451.1456$. 


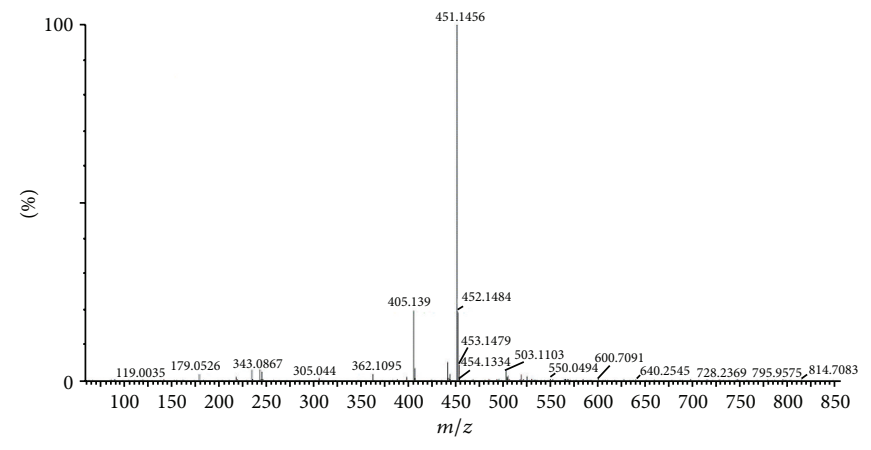

(a)

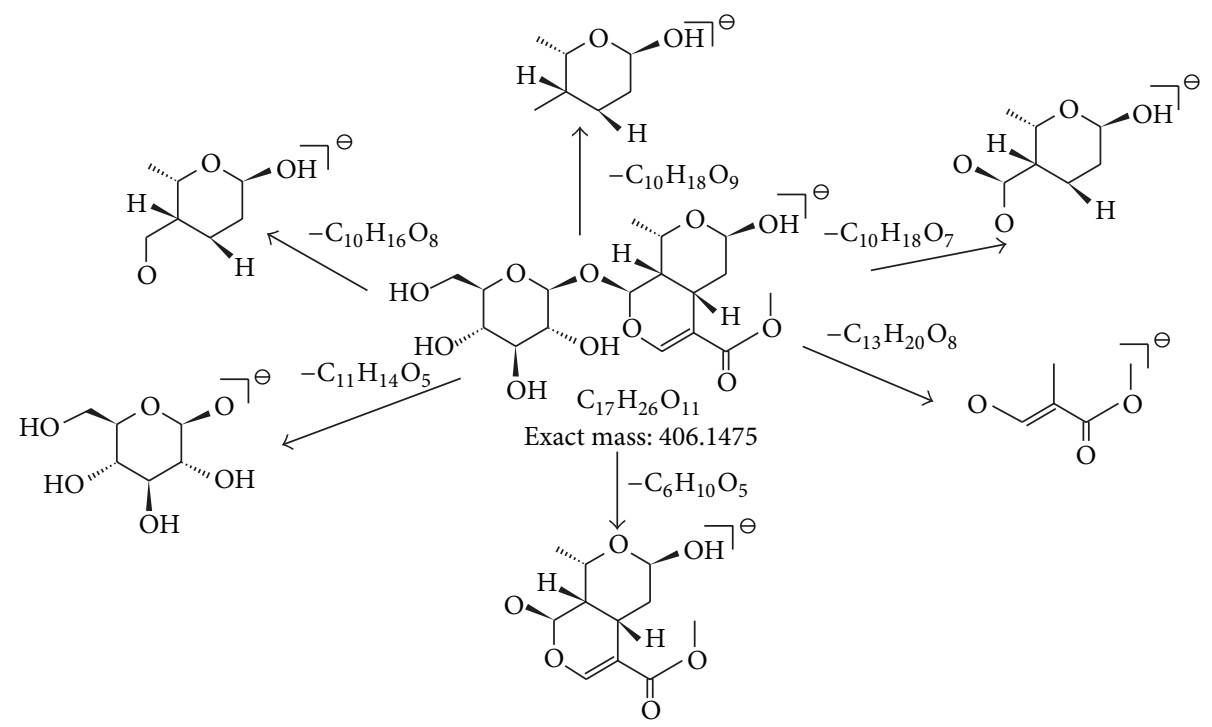

(b)<smiles>COC(=O)C1=COC(O)C2=C1CC(O)O[C@H]2C</smiles>

(c)

FIGURE 2: Proposed fragmentation pathways of morroniside and its metabolites from analysis of the rat urine samples: (a) accurate MS spectra of morroniside; (b) proposed fragmentation pathway of morroniside; and (c) proposed metabolic pathway of morroniside. 


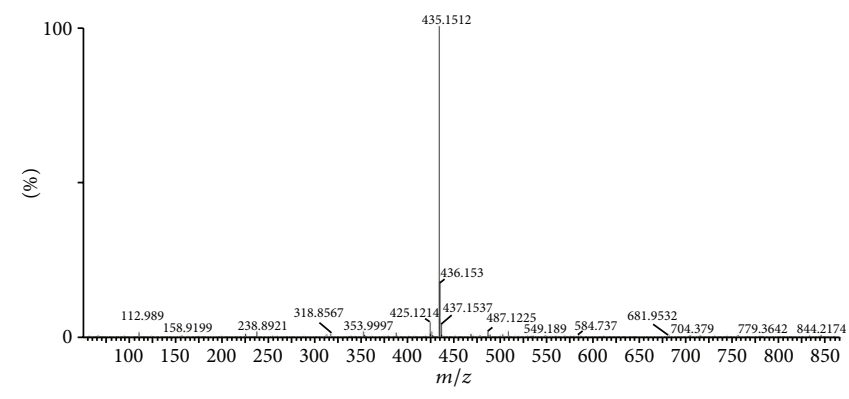

(a)

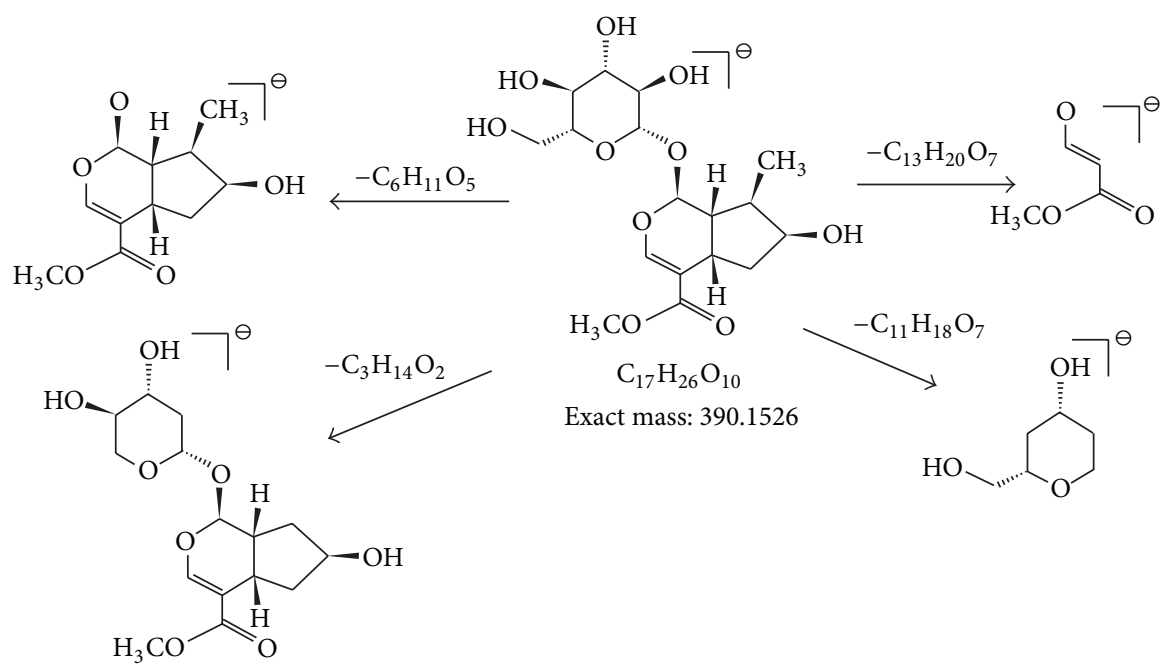

(b)

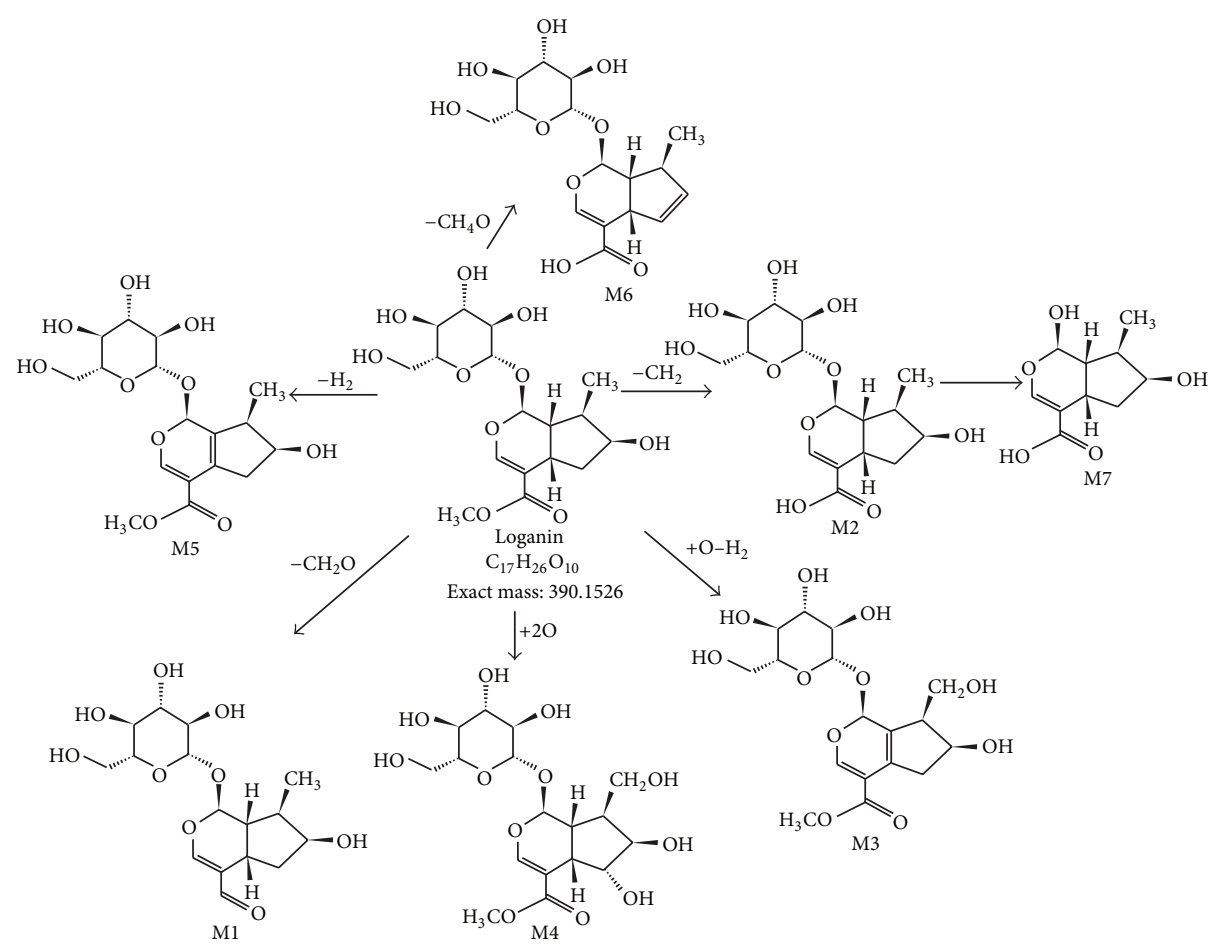

(c)

FIGURE 3: Proposed fragmentation pathways of loganin and its metabolites from analysis of the rat urine samples: (a) accurate MS spectra of loganin; (b) proposed fragmentation pathway of loganin; and (c) proposed metabolic pathway of loganin. 


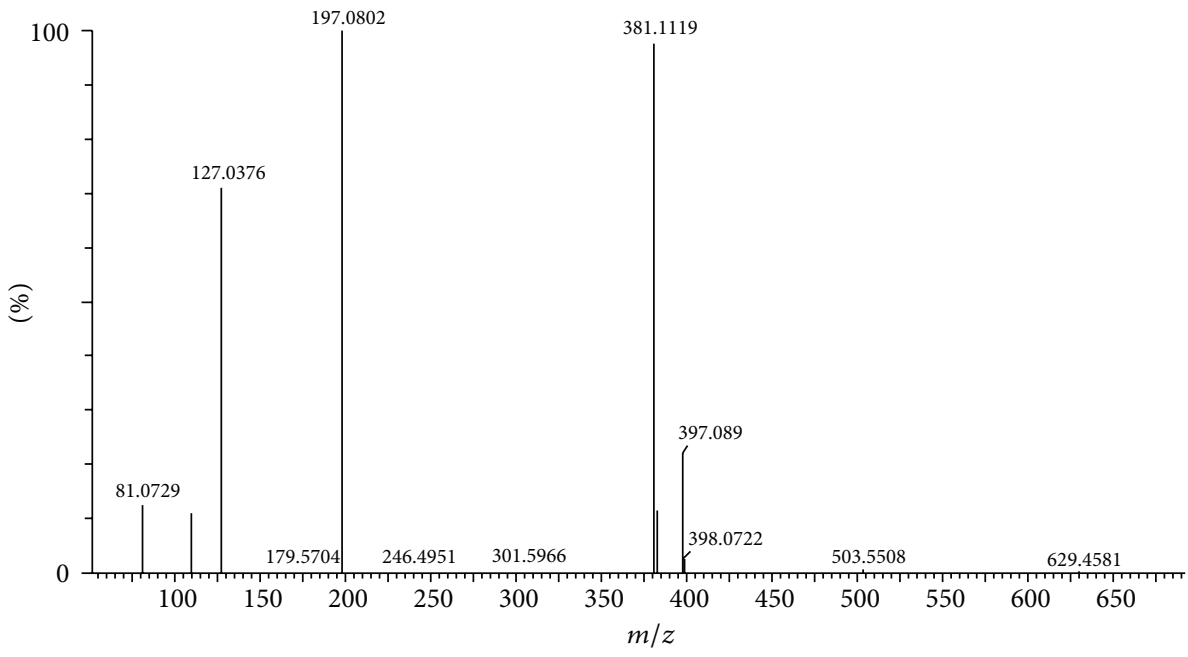

(a)

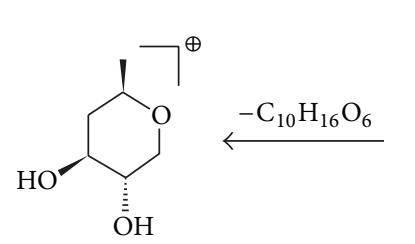<smiles>C=C[C@H]1[C@H](OC2O[C@H](CO)[C@@H](O)[C@H](O)[C@H]2O)OC=C2C(=O)OCC[C@H]21</smiles><smiles>CCCCCCO</smiles>

Exact mass: 358.1264

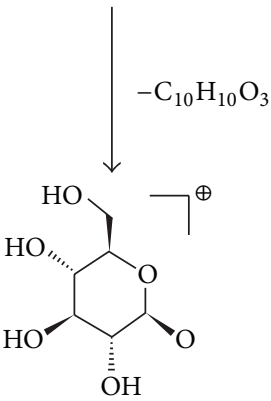

(b)<smiles>COCCC1=C[C@@H](O[C@@H]2O[C@H](CO)[C@@H](O)[C@H](O)[C@H]2O)OC=C1C(=O)O</smiles><smiles>CCC</smiles><smiles>C1CCCCC1</smiles><smiles>[CH2+]C</smiles><smiles>C=CC1=C2CCOC(=O)C2=CO[C@@H]1OC1OC(CO)[C@H](O)C(O)[C@H]1O</smiles>
M5<smiles>C=C[C@H]1[C@H](OC2OC(CO)[C@@H](O)C(O)[C@H]2O)OC=C2C(=O)OCCC[C@]21C</smiles>
Sweroside $\mathrm{C}_{16} \mathrm{H}_{22} \mathrm{O}_{9}$ Exact mass: 358.1264<smiles>C=C[C@H]1[C@H](OC2OC(CCC(C)=O)[C@@H](O)[C@H](O)[C@H]2O)OC=C2C(=O)OCC[C@]21O</smiles>
$\mathrm{HO}$<smiles>C=C[C@H]1[C@H](O)OC=C2C(=O)OCC[C@@H]21</smiles><smiles>[M]C=O</smiles>
$\mathrm{HO}$ "<smiles>C=CC1=C2CCOC(=O)C2=CO[C@H]1O</smiles>

(c)

FIGURE 4: Proposed fragmentation pathways of sweroside and its metabolites from analysis of the rat urine samples: (a) accurate MS spectra of sweroside; (b) proposed fragmentation pathway of sweroside; and (c) proposed metabolic pathway of sweroside. 


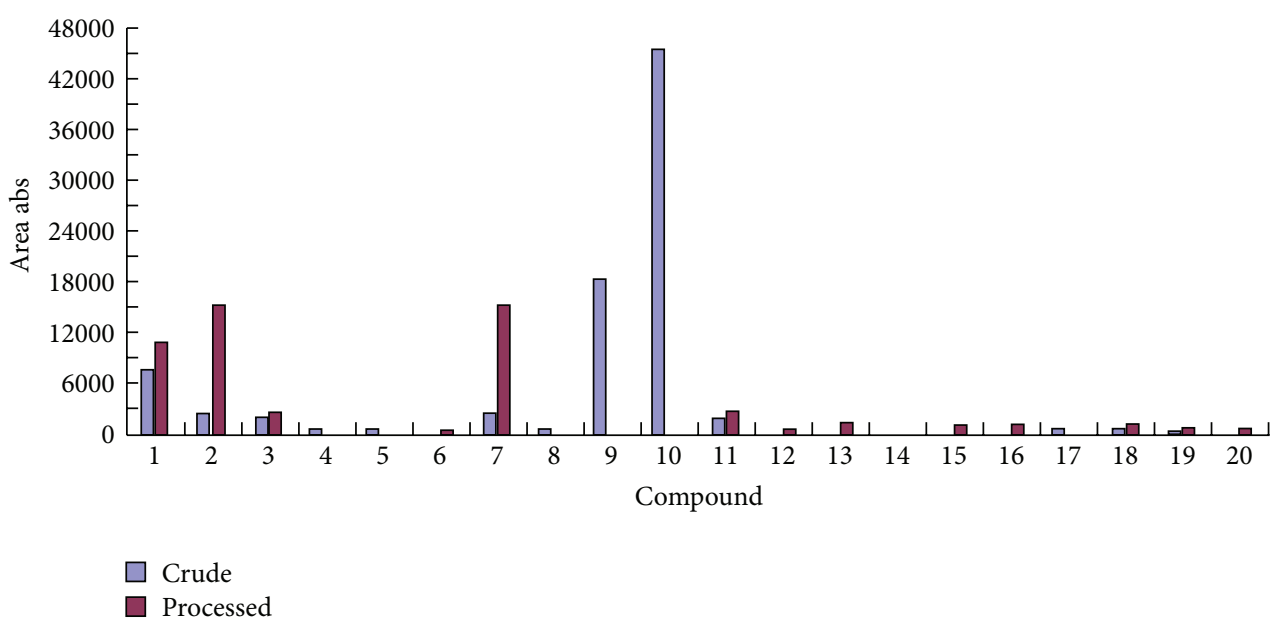

FIGURE 5: Parent compounds and metabolites detected in rat urines after oral administration of crude and processed cornus officinalis, respectively.

TABLE 1: The mass data of metabolites and parent components acquired using UPLC-QTOF/MS.

\begin{tabular}{|c|c|c|c|c|c|c|}
\hline No. & Compound & $T_{R}(\min )$ & Molecular formula & Molecular weight & QTOF/MS & Mass accuracy (ppm) \\
\hline 1 & Morroniside & 8.08 & $\mathrm{C}_{17} \mathrm{H}_{26} \mathrm{O}_{11}$ & 406.1473 & {$[\mathrm{M}+\mathrm{COOH}]^{-}$} & 0 \\
\hline 2 & M1-1 & 10.73 & $\mathrm{C}_{17} \mathrm{H}_{26} \mathrm{O}_{10}$ & 390.1526 & {$[\mathrm{M}-\mathrm{O}]^{-}$} & 0.6 \\
\hline 3 & M1-2 & 8.08 & $\mathrm{C}_{17} \mathrm{H}_{26} \mathrm{O}_{12}$ & 422.1195 & {$[\mathrm{M}+\mathrm{O}]^{-}$} & 0.5 \\
\hline 4 & M1-3 & 8.72 & $\mathrm{C}_{10} \mathrm{H}_{14} \mathrm{O}_{5}$ & 214.1053 & {$\left[\mathrm{M}-\mathrm{C}_{7} \mathrm{H}_{12} \mathrm{O}_{6}\right]^{-}$} & 0.4 \\
\hline 5 & M1-4 & 5.53 & $\mathrm{C}_{11} \mathrm{H}_{14} \mathrm{O}_{5}$ & 225.061 & {$\left[\mathrm{M}-\mathrm{C}_{6} \mathrm{H}_{12} \mathrm{O}_{6}\right]^{-}$} & 0.3 \\
\hline 6 & M1-5 & 23.9 & $\mathrm{C}_{18} \mathrm{H}_{28} \mathrm{O}_{13}$ & 452.159 & {$\left[\mathrm{M}+\mathrm{COOH}_{2}\right]^{-}$} & 0.4 \\
\hline 7 & Loganin & 10.60 & $\mathrm{C}_{17} \mathrm{H}_{26} \mathrm{O}_{10}$ & 390.1520 & {$[\mathrm{M}+\mathrm{COOH}]^{-}$} & 0 \\
\hline 8 & M2-1 & 7.5 & $\mathrm{C}_{16} \mathrm{H}_{24} \mathrm{O}_{9}$ & 360.1420 & {$\left[\mathrm{M}-\mathrm{OCH}_{2}\right]^{-}$} & 0.6 \\
\hline 9 & M2-2 & 6.28 & $\mathrm{C}_{16} \mathrm{H}_{24} \mathrm{O}_{10}$ & 376.1363 & {$\left[\mathrm{M}-\mathrm{CH}_{2}\right]^{-}$} & 0.2 \\
\hline 10 & M2-3 & 7.42 & $\mathrm{C}_{17} \mathrm{H}_{24} \mathrm{O}_{11}$ & 404.1313 & {$\left[\mathrm{M}+\mathrm{O}-\mathrm{H}_{2}\right]^{-}$} & 0.3 \\
\hline 11 & M2-4 & 8.05 & $\mathrm{C}_{17} \mathrm{H}_{26} \mathrm{O}_{12}$ & 422.1233 & {$\left[\mathrm{M}+\mathrm{O}_{2}\right]^{-}$} & 0.5 \\
\hline 12 & M2-5 & 7.5 & $\mathrm{C}_{17} \mathrm{H}_{24} \mathrm{O}_{10}$ & 388.1369 & {$\left[\mathrm{M}-\mathrm{H}_{2}\right]^{-}$} & 0.3 \\
\hline 13 & M2-6 & 10.47 & $\mathrm{C}_{16} \mathrm{H}_{22} \mathrm{O}_{9}$ & 358.1264 & {$\left[\mathrm{M}-\mathrm{CH}_{4} \mathrm{O}\right]^{-}$} & 0.1 \\
\hline 14 & M2-7 & 23.96 & $\mathrm{C}_{11} \mathrm{H}_{14} \mathrm{O}_{7}$ & 452.1590 & {$\left[\mathrm{M}-\mathrm{CH}_{2}-\mathrm{C}_{6} \mathrm{H}_{10} \mathrm{O}_{5}\right]^{-}$} & 0.4 \\
\hline 15 & Sweroside & 10.47 & $\mathrm{C}_{16} \mathrm{H}_{22} \mathrm{O}_{9}$ & 358.1256 & {$[\mathrm{M}+\mathrm{Na}]^{+}$} & 0 \\
\hline 16 & M3-1 & 10.48 & $\mathrm{C}_{10} \mathrm{H}_{12} \mathrm{O}_{4}$ & 196.0736 & {$\left[\mathrm{M}-\mathrm{C}_{6} \mathrm{H}_{10} \mathrm{O}_{5}\right]^{+}$} & 0.6 \\
\hline 17 & M3-2 & 8.08 & $\mathrm{C}_{10} \mathrm{H}_{10} \mathrm{O}_{4}$ & 194.0579 & {$\left[\mathrm{M}-\mathrm{C}_{6} \mathrm{H}_{10} \mathrm{O}_{5}-\mathrm{H}_{2}\right]^{+}$} & 0.2 \\
\hline 18 & M3-3 & 7.33 & $\mathrm{C}_{16} \mathrm{H}_{22} \mathrm{O}_{10}$ & 374.0818 & {$[\mathrm{M}+\mathrm{O}]^{+}$} & 0.5 \\
\hline 19 & M3-4 & 2.65 & $\mathrm{C}_{14} \mathrm{H}_{18} \mathrm{O}_{9}$ & 330.0951 & {$\left[\mathrm{M}-\mathrm{CH}_{2}-\mathrm{CH}_{2}\right]^{+}$} & 0.3 \\
\hline 20 & M3-5 & 6.35 & $\mathrm{C}_{16} \mathrm{H}_{20} \mathrm{O}_{9}$ & 356.1107 & {$\left[\mathrm{M}-\mathrm{H}_{2}\right]^{+}$} & 0.4 \\
\hline
\end{tabular}

The corresponding fragment ions, including $\mathrm{m} / \mathrm{z} 101.0273$ $\left[\mathrm{M}-\mathrm{C}_{13} \mathrm{H}_{20} \mathrm{O}_{8}\right]^{-}, \quad m / z \quad 123.0373 \quad\left[\mathrm{M}-\mathrm{C}_{10} \mathrm{H}_{18} \mathrm{O}_{9}\right]^{-}, \quad m / z$ $141.0547\left[\mathrm{M}-\mathrm{C}_{10} \mathrm{H}_{16} \mathrm{O}_{8}\right]^{-}, m / z \quad 155.0334\left[\mathrm{M}-\mathrm{C}_{10} \mathrm{H}_{18} \mathrm{O}_{7}\right]^{-}$, $m / z 179\left[\mathrm{M}-\mathrm{C}_{11} \mathrm{H}_{14} \mathrm{O}_{5}\right]^{-}, m / z 243.0825\left[\mathrm{M}-\mathrm{C}_{6} \mathrm{H}_{10} \mathrm{O}_{5}\right]^{-}$, and $\mathrm{m} / z 405.1390[\mathrm{M}-\mathrm{H}]^{-}$, were also identified in MS spectra of high-collision energy scan. Compound 1 was identified as morroniside through comparison with standard.

Five metabolites of morroniside were detected from the rat urine using $\mathrm{MS}^{\mathrm{E}}$ approach and MetaboLynx, with most of the constituents $[\mathrm{M}-\mathrm{H}]^{-}$being observed in the (-) ESI-MS spectra from $\mathrm{MS}^{E}$ data. Moreover, the characteristic fragment peaks of the parent compound related to the metabolite were observed. The high-collision energy scan fragment ions of
M1-1 at $m / z 390.1526[\mathrm{M}-\mathrm{O}]^{-}, \mathrm{M} 1-2$ at $m / z 422.1195[\mathrm{M}+\mathrm{O}]^{-}$, M1-3 at $m / z 214.1053\left[\mathrm{M}-\mathrm{C}_{7} \mathrm{H}_{12} \mathrm{O}_{6}\right]^{-}, \mathrm{M} 1-4$ at $m / z 225.061$ $\left[\mathrm{M}-\mathrm{C}_{6} \mathrm{H}_{12} \mathrm{O}_{6}\right]^{-}$(loss of a glucose group), and M1-5 at $\mathrm{m} / z$ $425.159\left[\mathrm{M}+\mathrm{COOH}_{2}\right]^{-}$were observed. After being processed with the mass defect filter, their possible metabolites were detected in combination the with related literature data or METLIN's metabolite mass spectral database, shown in Table 1. The pathways of morroniside and metabolites are shown in Figure 2.

3.2.2. Identification of Parent Compound 2 and Its Metabolites. Compound 2 showed an $[\mathrm{M}+\mathrm{COOH}]^{-}$ion at $\mathrm{m} / z 435.1512$ at $30 \mathrm{~V}$. It also yielded product ions, including $\mathrm{m} / z 101.0143$ 
$\left[\mathrm{M}-\mathrm{C}_{13} \mathrm{H}_{20} \mathrm{O}_{7}\right]^{-}, m / z 127\left[\mathrm{M}-\mathrm{C}_{11} \mathrm{H}_{18} \mathrm{O}_{7}\right]^{-}$, and $m / z 227.0905$ $\left[\mathrm{M}-\mathrm{C}_{6} \mathrm{H}_{10} \mathrm{O}_{5}\right]^{-}$. Compound 2 was identified as loganin by comparison with standard.

Seven metabolites of morroniside were identified in the rat urine according to their retention time qualities, and MS/MS fragment ions. The high-collision energy scan fragment ions of M2- 1 at $m / z 360.1420\left[\mathrm{M}-\mathrm{OCH}_{2}\right]^{-}, \mathrm{M} 2-2$ at $\mathrm{m} / z$ $376.1363\left[\mathrm{M}-\mathrm{CH}_{2}\right]^{-}, \mathrm{M} 2-3$ at $\mathrm{m} / z 404.1313\left[\mathrm{M}+\mathrm{O}-\mathrm{H}_{2}\right]^{-}$, M24 at $m / z 422.1233\left[\mathrm{M}+\mathrm{O}_{2}\right]^{-}, \mathrm{M} 2-5$ at $m / z 388.1369\left[\mathrm{M}-\mathrm{H}_{2}\right]^{-}$, M2-6 at $\mathrm{m} / z$ 358.1264 $\left[\mathrm{M}-\mathrm{CH}_{4} \mathrm{O}\right]^{-}$, and $\mathrm{M} 2-7$ at $\mathrm{m} / z$ $452.1590\left[\mathrm{M}-\mathrm{CH}_{2}-\mathrm{C}_{6} \mathrm{H}_{10} \mathrm{O}_{5}\right]^{-}$were observed. The pathways of loganin and metabolites are shown in Figure 3.

3.2.3. Analysis of Parent Compound 3 and Its Metabolites. Compound 3 gave an $[\mathrm{M}+\mathrm{Na}]^{+}$ion at $m / z 381.1119$ with a fragmentor voltage of $25 \mathrm{~V}$. It also yielded product ions at $\mathrm{m} / \mathrm{z}$ $127.0376\left[\mathrm{M}-\mathrm{C}_{10} \mathrm{H}_{16} \mathrm{O}_{6}\right]^{+}$and $m / z 197.0802\left[\mathrm{M}-\mathrm{C}_{6} \mathrm{H}_{10} \mathrm{O}_{5}\right]^{+}$. Compound 3 was identified as sweroside by comparison with standard.

Five metabolites of sweroside were detected from the rat urine using MetaboLynx software. The high-collision energy scan fragment ions of M3-1 at $m / z 196.0736\left[\mathrm{M}-\mathrm{C}_{6} \mathrm{H}_{10} \mathrm{O}_{5}\right]^{+}$, M3-2 at $\mathrm{m} / z$ 194.0579 $\left[\mathrm{M}-\mathrm{C}_{6} \mathrm{H}_{10} \mathrm{O}_{5}-\mathrm{H}_{2}\right]^{+}, \mathrm{M} 3-3$ at $\mathrm{m} / \mathrm{z}$ $374.0818[\mathrm{M}+\mathrm{O}]^{+}, \mathrm{M} 3-4$ at $\mathrm{m} / z$ 330.0951 $\left[\mathrm{M}-\mathrm{CH}_{2}-\mathrm{CH}_{2}\right]^{+}$, and M3-5 at $m / z 356.1107\left[\mathrm{M}-\mathrm{H}_{2}\right]^{+}$were observed. The pathways of sweroside and metabolites are shown in Figure 4.

3.3. The Influence of Rice Wine on the Contents of Main Compounds and Their Metabolites. Three parent compounds and seventeen metabolites were identified in the rat urine by UPLC-QTOF/MS after i.g. administration of aqueous extracts of crude Cornus officinalis and its processed extracts. In crude Cornus officinalis samples, thirteen metabolites were detected, but metabolites including M1-5, M2-5, M2-6, M27, M3-1, M3-5, and one parent compound (sweroside) were not found in the rat urine. It is possible that sweroside may have been transformed into its metabolites. For processed Cornus officinalis samples, six metabolites, including M1-3, M1-4, M2-1, M2-2, M2-3, and M3-2, were not detected in the rat urine. The peak intensities of parent compounds and metabolites in both crude and processed Cornus officinalis varied significantly. Moreover, the contents of compounds were dramatically decreased in Cornus officinalis after processing by rice wine. The results are shown in Figure 5.

\section{Conclusion}

In this work, UPLC-QTOF/MS was used to investigate the excretion of extracts of crude and processed Cornus officinalis in rat urine. Three parent compounds and seventeen metabolites were identified, demonstrating the analytical potential of this method for metabolism studies. Our study highlights the importance of UPLC-QTOF/MS as a potential tool for uncovering the effect of rice wine on metabolites of the main components of herbal medicine, in vivo, to predict and discover processing mechanisms of herbal medicine. It can therefore be used for studies of excipient treatment in processing of herbal medicine.

\section{Authors' Contribution}

G. Cao and H. Cai contribute equally to this work.

\section{Acknowledgments}

The authors are grateful for the financial support from the following: the National Natural Science Foundation of China (nos. 81274056, 81202918, 30873438, 30940093, and 81173546), the Medical Scientific Research Foundation of Zhejiang Province, China (no. 2013KYB183), the Natural Science Foundation of Jiangsu Province, China (no. BK2009495), the International Science and Technology Cooperation Project of Zhejiang Province, China (nos. 2012D60SA1C0065 and 2012D60SA1C0066), the International Science and Technology Cooperation Project of Jiangsu Province, China (no. BZ2011053) the Open Project of National First-Class Key Discipline for Science of Chinese Materia Medica, Nanjing University of Chinese Medicine (no. 2011ZYX2-006, no. 2011ZYX2-001), the Project of Science and Technology for Chinese Medicine of Zhejiang province, China (no. 2009CB008), the fund of Zhejiang Modernization of Traditional Chinese Medicine Item ([2008]436), the Chinese Medicine Research Program of Zhejiang Province, China (nos. 2008ZA002, 2011ZB101), and the Science Foundation of Zhejiang Chinese Medical University (no. 7211093).

\section{References}

[1] H. W. Yao and Y. Liu, "Study of the processing of chinese herbal medicine: status quo and development strategy," China Pharmacy, vol. 30, pp. 2394-2396, 2008.

[2] K. M. Qin, Y. Shi, X. H. Tan, T. L. Lu, H. Wu, and B. C. Cai, "Application of modern instrumental analytical techniques in the mechanism research of chinese medicine processing," Scientia Sinica, vol. 6, pp. 668-678, 2010.

[3] Z. Y. Li, H. P. Zhang, L. Jiang, and T. N. He, "Analysis of frace elements from supplementary materials in traditional Chinese medicine," Journal of Yunnan Normal University, vol. 1, pp. 2527, 2002.

[4] M. F. Ma, W. Lv, and Y. Y. Gao, "Reseach on excipient of traditional Chinese medicine," The Journal of Chinese Medicine \& Traditional Chinese Medicine, vol. 3, pp. 22-24, 2005.

[5] M. A. Presta, B. Bruyneel, R. Zanella, J. Kool, J. G. Krabbe, and H. Lingeman, "Determination of flavonoids and resveratrol in wine by turbulent-flow chromatography-LC-MS," Chromatographia, vol. 69, no. 2, pp. S167-S173, 2009.

[6] M. Boban and D. Modun, "Uric acid and antioxidant effects of wine," Croatian medical journal, vol. 51, no. 1, pp. 16-22, 2010.

[7] S. Das, D. D. Santani, and N. S. Dhalla, "Experimental evidence for the cardioprotective effects of red wine," Experimental and Clinical Cardiology, vol. 12, no. 1, pp. 5-10, 2007.

[8] Z. Q. Mao and X. R. Xuan, "Innovations in the production of yellow rice wine," Food and Fermentation Technology, vol. 1, pp. 10-12, 2009.

[9] J. Z. Yu, X. Wang, Z. Y. He, and J. Chen, "Comparative analysis of nutritional and functional components of yellow rice wine from different fields," Journal of Anhui Agricultural Sciences, vol. 32, pp. 15989-15991, 2009.

[10] G. Cao, C. Zhang, Y. Zhang et al., "Global detection and identification of components from crude and processed traditional 
Chinese medicine by liquid chromatography connected with hybrid ion trap and time-of-flight-mass spectrometry," Journal of Separation Science, vol. 34, no. 15, pp. 1845-1852, 2011.

[11] L. L. Zhou, G. G. Wu, Z. Q. Liu, and S. Y. Liu, "Studies on the components of crude and processed fructus corni by ESI-MS"," Chemical Research in Chinese Universities, vol. 24, no. 3, pp. 270274, 2008.

[12] Z. Q. Fu, M. Y. Wang, and B. C. Cai, "Discussion of 5hydroxymethylfurfural (5-HMF) in Chinese native medicine research present situation," Chinese Archives of Traditional Chinese Medicine, vol. 26, pp. 508-510, 2008.

[13] X. Ding, M. Y. Wang, Z. L. Yu, W. Hu, and B. C. Cai, "Studies on separation, appraisal and the biological activity of 5-HMF in Cornus officinalis," China Journal of Chinese Materia Medica, vol. 33, no. 4, pp. 392-484, 2008.

[14] G. Cao, H. Cai, Y. Zhang, X. Cong, C. Zhang, and B. Cai, "Identification of metabolites of crude and processed Fructus Corni in rats by microdialysis sampling coupled with electrospray ionization linear quadrupole ion trap mass spectrometry," Journal of Pharmaceutical and Biomedical Analysis, vol. 56, no. 1, pp. 118-125, 2011.

[15] G. Cao, Y. Zhang, X. D. Cong, H. Cai, and B. C. Cai, "Research progress on the chemical constituents and pharmacological activities of Fructus corni," Journal of Chinese Pharmaceutical Sciences, vol. 18, pp. 208-213, 2009.

[16] G. Cao, Y. Zhang, Q. Y. Shan et al., "Pharmacokinetic parameters of morroniside in iridoid glycosides of Fructus corni processing based on back-propagation neural network," Pharmaceutical Biology, vol. 49, pp. 989-993, 2011.

[17] L. Liu, A. Sun, S. Wu, and R. Liu, "Preparative purification of morroniside and loganin from fructus corni by combination of macroporous absorption resin and HSCCC," Journal of Chromatographic Science, vol. 47, no. 5, pp. 333-336, 2009.

[18] T. Yokozawa, C. H. Park, J. S. Noh, T. Tanaka, and E. J. Cho, "Novel action of 7-O-galloyl-D-sedoheptulose isolated from Corni Fructus as a hypertriglyceridaemic agent," Journal of Pharmacy and Pharmacology, vol. 61, no. 5, pp. 653-661, 2009.

[19] X. Li, Q. Wang, X. Zhang et al., "HPLC study of pharmacokinetics and tissue distribution of morroniside in rats," Journal of Pharmaceutical and Biomedical Analysis, vol. 45, no. 2, pp. 349355, 2007.

[20] L. T. Zhang, L. M. Ren, and J. K. Wun, "Studies on pharmacokinetics of loganin and morroniside in Cornus officinalis injection in mice," China Journal of Chinese Materia Medica, vol. 28, no. 6, pp. 509-512, 2003.

[21] Y. D. Luo, J. Chen, J. Cao, X. D. Wen, and P. Li, "Determination of sweroside in rat plasma and bile for oral bioavailability and hepatobiliary excretion," Chemical and Pharmaceutical Bulletin, vol. 57, no. 1, pp. 79-83, 2009. 


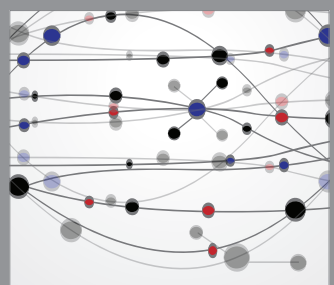

The Scientific World Journal
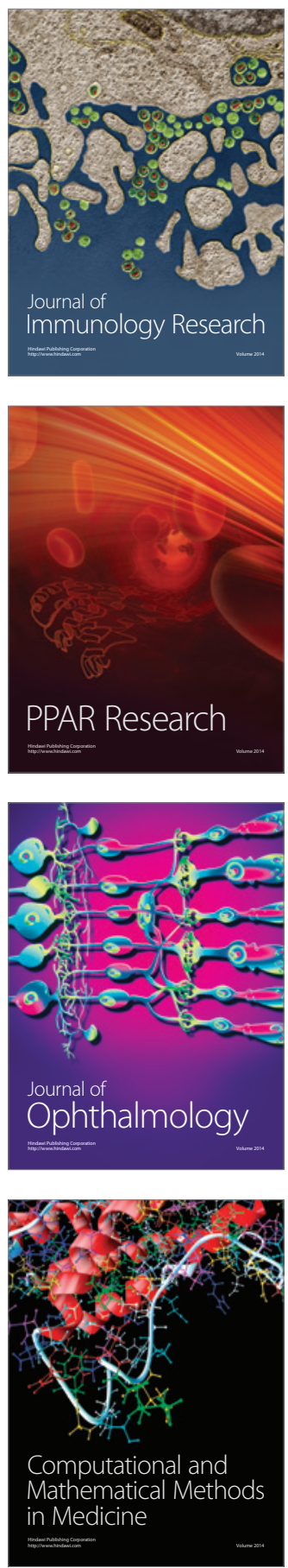

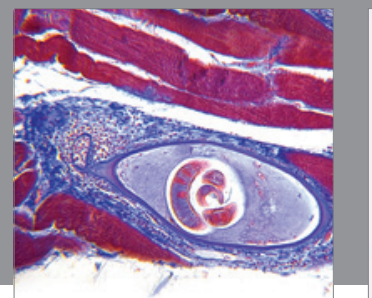

Gastroenterology

Research and Practice
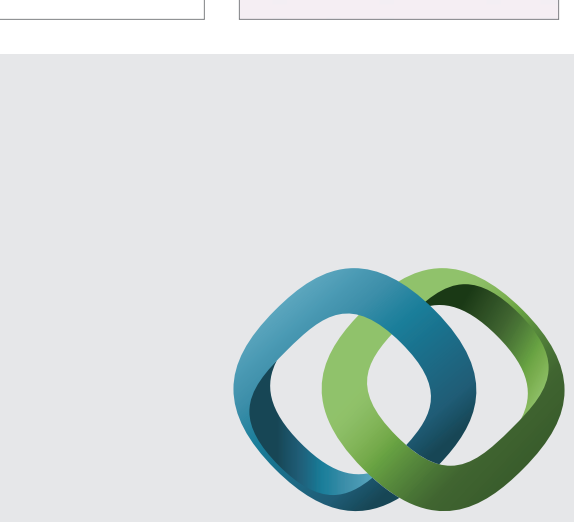

\section{Hindawi}

Submit your manuscripts at

http://www.hindawi.com
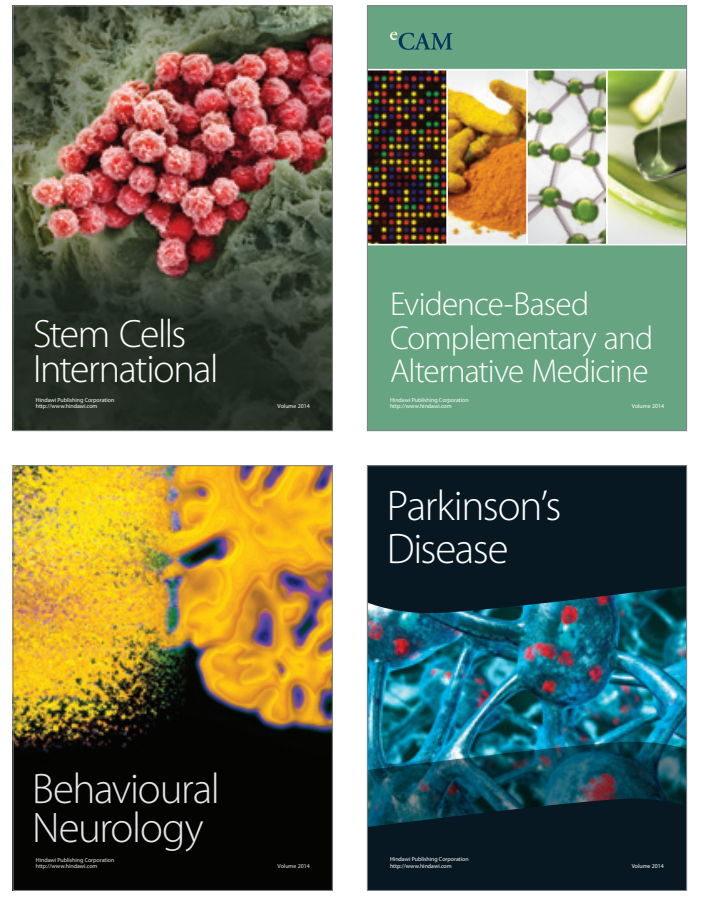
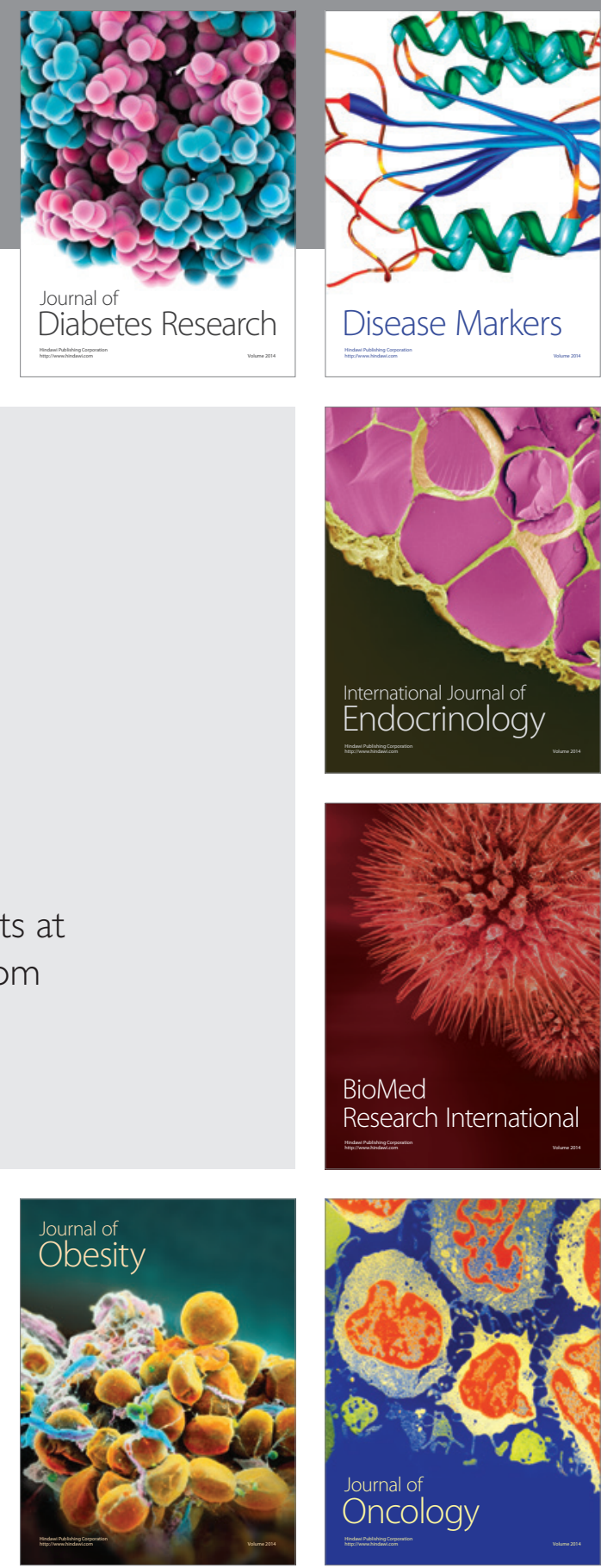

Disease Markers
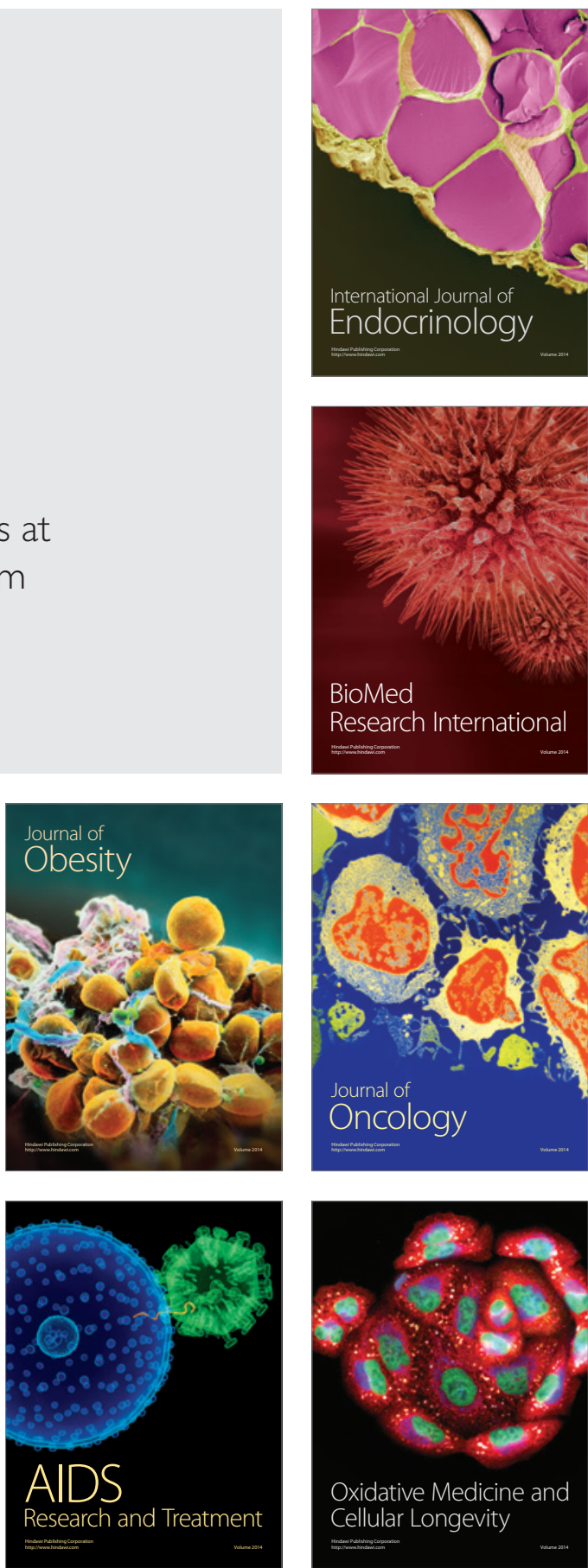